\title{
BRASSINOSTEROIDS IN BREEDING TECHNOLOGIES HEALTHCARE POTATO
}

\author{
Irina Pavlovna Uromova, \\ Olga Veniaminovna Shtyrlina, Natalia Nikolaevna Koposova, \\ Andrew Vladimirovich Kozlov and Dmitry Aleksandrovich Shtyrlin
}

\author{
Minin Nizhniy Novgorod State Pedagogical University, \\ Ulyanova Street, 1, Nizhniy Novgorod, GSP-37, 603950 Russia
}

Received 2014-05-26; Revised 2014-06-17; 2014-08-08

\begin{abstract}
The regulator of anti-stress action Epin-Extra (24-epibrassinolide) was tested in laboratory and field (protected ground) conditions. The aim of this research was to study the influence of growth regulators on the growth, development and productivity of improved initial promising varieties of potato: Native (cultivated varieties Udacha) and foreign (cultivated varieties Red Scarlett) selections obtained by the method of apical meristem in the Volga-Vyatka region. The obtained results suggest a promising use of the product for improving the growth and development of plants in vitro. Adding Epin-Extra into an artificial culture medium at the final stage of micropropagation in vitro increases the height of plants by 29.6-47.7\%, the number of internodes in plants by $26.4-25.7 \%$ depending on the cultivated variety, increases the root growth for cultivar Udacha 2.1 times and reduces the one for the cultivar Red Scarlett 1.9 times. The use of the Epin-Extra product-in recommended concentration for growing mini-tubers by seedling method in protected soil (greenhouse) in the budding phase-increases the biometric indicators such as plant height (35.7-21.8\%), number of stems in the bush (30.9-19.0\%) and mass of roots $(19.1-8.5 \%)$, depending on the variety. As a result, the treatment with Epin-Extra increases productivity by $25.6-15.9 \%$, the multiplication factor by $25.3-18.4 \%$, as well as helps to reduce the prevalence (by 69.5-44.1\%) and development (by 50.0$44.3 \%$ ) of the late blight on the tops of potato plants, depending on the cultivar.
\end{abstract}

Keywords: Epin-Extra, Anti-Stress Regulator, In Vitro, Apical Meristem, Micrograftage, Murashige-Skoog Medium, The Yield of Potato, Late Blight

\section{INTRODUCTION}

In order to provide a sustainable potato production, the improvement of its seeds quality is of great importance. Currently, this problem is successfully solved in virus-free system of potato plant propagation cultivars improvement, cloning micropropagation, as well as widespread utilization in agricultural production the ready-to-use improved material (Anisimov, 2003).

In terms of cultivation technology enhancement of the improved potato, the actual direction is the use of through the application of biotechnological techniques of

growth regulators with high biological activity, which are considered to be environmentally safe means of increasing the productivity of cultivated plants (Tarazanova and Ignatiev, 2013; Mohapatra et al., 1993; Korp, 1989; Harmey et al., 1966). Those growth regulators include the compounds of brassinosteroids class-naturally occurring plant hormones (Kagale, 2007). Brassinosteroids provide a harmonious growth and development of plants in all stages of their ontogeny, increasing their resistance to stress, pests and diseases and as a result, the productivity increase and product quality improvement can be observed (Persikova and Corresponding Author: Irina Pavlovna Uromova, Minin Nizhniy Novgorod State Pedagogical University, Ulyanova Street, 1, Nizhniy Novgorod, GSP-37, 603950 Russia 
Hodyankov, 2008; Hartz and Johnstone, 2006). Epinformulation of brassinosteroids-is considered to be one of the best anti-stress stimulators (Kravchenko, 2004; Hirsch, 1997). Thereby, the aim of our research is to determine the influence of the Epin-Extra growth regulator on the growth and development of the meristem plants and their productivity if the mini-tubers are being grown up in protected soil (greenhouse).

\section{MATERIAL AND METHODS}

The experimental part was done in the biotechnical laboratory and the greenhouse of LLC "Elithoz" in Borsky district of Nizhny Novgorod region during 20082010 years. In experiments the improved material of two potato cultivars Udacha (native breeding) and Red Scarlett (foreign breeding) were used. The experimental setup included two variants: 1 (control)-a standard nutrient medium Murashige-Skoog (MS); 2 (experiment)-MS + Epin. The concentration of Epin in the laboratory experiment was $0.25 \mathrm{mg} \mathrm{L}^{-1}$ (based on the published data). Epin-Extra was added to the culture medium at the last stage of graftage. The biometrics of plants was determined in the laboratory in vitro.

Field experiments were set and statistically processed in accordance with the established procedure (Dospekhov, 1985). The total area of the plot was $28 \mathrm{~m}^{2}$, an account zone-14 $\mathrm{m}^{2}$, four-time repetitions of the experiment, the location of the plots was systematical. Planting scheme- $70 \times 24 \mathrm{~cm}$. Single aerial spraying of the plants was carried out during the growing season. The concentration of the product corresponded to the recommended instructions. Treatments were done with manual knapsack sprayer. During the vegetating period in protected soil (greenhouse) plants biometrics as well as the spread of the diseases on potato tops and crop yield were determined.

\section{RESULTS}

Adding the growth regulator Epin-Extra $(0.25 \mathrm{mg}$ $\mathrm{L}^{-1}$ ) into an artificial medium at the last stage of micropropagation of potato plants in vitro induces the acceleration of growth processes (29.6-47.7\%), increases the number of internodes in microplants, depending on the cultivar by $26.4-25.7 \%$ and enhances the roots growth for the cultivated variety Udacha 2.1 times, but for the cultivar Red Scarlett, reduces the root growth 1.9 times.

The use of the product Epin-Extra-in recommended, optimal concentration for growing mini-tubers by seedling method helps to obtain a 35.7-21.8\% increase in the height of plants, a $30.9-19.0 \%$ increase in the number of stems in the bush and a 19.1-8.5\% increase in the mass of roots, depending on the cultivar.

Application of Epin-Extra in growing mini-tubers seedling method enhances the productivity by 25.6$15.9 \%$ as well as the net reproduction rate by 25.3$18.4 \%$, depending on the cultivated variety.

The use of Epin-Extra in protected soil helped to reduce the prevalence $(69.5-44.1 \%)$ and development (50.0-44.3\%) of late blight on the tops of potato.

\section{DISCUSSION}

The research has proved that the application of the Epin-Extra growth regulator at the last stage of micrograftage by adding it to an artificial nutrient medium has a certain effect on potato microplants growth and development in vitro for the described cultivars (Table 1).

The application of the Epin-Extra product had a positive effect on plants height of both cultivated varieties of potato. The degree of influence of the product depended on the cultivar. So, the Udacha cultivar was less responsive to the product effects-an increase by $29.6 \%$ was observed, while for the Red Scarlett cultivar, it was $47.7 \%$ compared with the control group. Consequently, Red Scarlett cultivar has more responded to the application of Epin-Extra.

The adding of Epin-Extra into the medium increased the number of internodes of plants and, consequently, the reproduction rate while micrograftage in vitro. During the 3 years of research, the average increase in the number of internodes of potato microplants depending on the cultivar was by $26.4-25.7 \%$, if compared with the control groups. The cultivated variety Udacha was the most responsive to the action of the product (by $0.7 \%$ ).

Biological product had the opposite effect on root growth of in vitro potato of the varieties being studied. The use of the product caused a decrease in the length of the root system of the plants of the cultivar Red Scarlett1.9 times, while the plants of the cultivar Udacha, contrarily, increased their root length-2.1 times compared with the control group. However, due to increased root formation and the number of internodes, microplants of Udacha cultivar varieties had a compact habit with well-developed root system.

It should be mentioned that during the 3-years research, for the potato plants grown with the use of Epin-Extra at the last stage of micrograftage, no 
morphological changes in shape, size, color and pubescence of the leaf blades and stems were detected. Some researchers (Hodyankov, 2008; Kravchenko, 2004; Dann and Deuereal, 2000) point out that the application of anti-stress products supports the stability of plants morphological structures. Therefore, the Epin-Extra in this particular concentration does not cause any modificational changes of potato culture associated with changes in the phenotype and which generally have the adaptive nature.

When growing mini-tubers in greenhouse, the use of the product facilitated the increase in plants biometric indicators (Table 2).

Epin-Extra had a significant impact on the number of stems of the studied varieties. Compared with the control groups, the excess for cultivar Udacha was $30.9 \%$ and for Red Scarlett one-19.0\%. Besides the increase in the stems number in shrub, an increase in the average length of the main stem as one of the main indicators characterizing the development of plants was noted: 15.3 $\mathrm{cm}(35.7 \%)$ more for cultivar Udacha and $8.9 \mathrm{~cm}$ (21.8\%) more for Red Scarlett one. Simultaneously with the increase in aboveground plant parts, an increase in the roots mass in both grades was determined: 19.1$8.5 \%$, respectively. And this is despite the fact that the test-tube plants of Red Scarlett cultivated in laboratory experiments had the root length significantly lower than those of the control one.

The results of the previous experiments (Uromova, 2009) suggest that the power of the root system of potato plants determines the resistance to adverse conditions as well as the plant productivity. Plants with more developed root system use more productively the nutrients and moisture from the soil; they are less affected by drought and waterlogging.

Thus, the Epin-Extra had a positive impact on the growth processes of potato plants. Also, the other positive moment of this stimulation is the fact that an increase in total experimental plants biomass has contributed to an increase in tuber parts of the plant, i.e., to the increase in potato productivity (Table 3 ).

The use of the Epin-Extra, in the process of growing the mini-tubers by seedling method in protected soil, not only provided an increase in plant height and number of stems of potatoes in the bush, but also had a positive impact on productivity and quantitative yield of experimental varieties of mini-tubers. Thus, the native cultivar Udacha demonstrated the greatest yield and the number of mini-tubers increase when using Epin-Extra. In this case, the average 3-years gain of this cultivated variety plants in mass and number of tubers was 98.4 grams of weight and 1.8 units comparing with control groups. Less obvious, but also reliable yield and the number of mini-tubers increases were obtained for cultivar Red Scarlett. 3 years average yield increase when using the Epin-Extra was $53.6 \mathrm{~g} / \mathrm{plant}$. And the number of mini-tubers increased by 1.4 units/plant. However, the net reproduction rate of the cultivar Red Scarlett in numerical value was slightly higher than for the variety Udacha and the weight of tubers was smaller and hence the potato crop was lower.

It is obvious that the Epin-Extra biological product, when adding it in an artificial medium and treating the vegetative plants with it at certain concentrations, stimulates high biological activity. It contributes to the harmonious growth and development of plants (both in vitro and in protected soil for growing seedling method), increases the stability of greenhouse plants to stress and diseases and as a consequence, the productivity, especially of the native cultivated variety.

During three years of research of the potato plantsm the only form of fungal diseases was noted-the late blight. Seeing the fact that in the experiments only improved seed material produced by the method of apical meristem was used, neither bacterial nor viral diseases have been identified.

The results of phytopathologic surveys showed that the degree of late blight lesion was various and depended on the potato varieties and humidity conditions in the greenhouse (Table 4).

Compared with control groups, the use of Epin-Extra contributed the greatest reduction in prevalence $(69.5 \%)$ and development $(50.0 \%)$ of late blight on cultivar Udacha. For the Red Scarlett one the product was less efficient (44.1-44.3\%, respectively). These surveys indicate minor differences blight infestation during the years of research, as moisture level in a greenhouse does not depend on weather conditions, which was also mentioned in the results of other researchers (Smidt and Negorek, 1977; Kus, 2000).

It is proved that the prevalence and development of late blight on potato tops mostly depend on the application of anti-stress phytoregulator Epin-Extra in order to protect the plants from disease and less on the cultivated variety characteristics. However, the Udacha cultivar's resistance to late blight maintained throughout all the years of experiment, only the absolute figures of disease prevalence and development change and this is confirmed by the data obtained in terms of field experiments (Uromova et al., 2013). 
Table 1. Influence of Epin-Extra onto the growth and the development of potato microplants in vitro (on the average for 2008-2010) Plant Height, mm

\begin{tabular}{lcccc} 
Variation & In 10 days & In 30 days & Number of internodes, piece & Roots length, mm \\
\hline Cultivar Udacha & & & & 32.0 \\
Medium MS (control) & 18.1 & 57.7 & 6.8 & 66.7 \\
MS + Epin-Extra & 34.0 & 74.8 & 0.6 & 9.5 \\
$\mathrm{HCP}_{05}$ & 2.1 & 4.3 & & 34.1 \\
Cultivar Red Scarlett & & & 7.0 & 18.3 \\
Medium MS (control) & 17.5 & 61.0 & 8.8 & 5.7 \\
$\mathrm{MS}_{+}$Epin-Extra & 37.4 & 90.1 & 1.1 & \\
$\mathrm{HCP}_{05}$ & 3.5 & 5.1 & & \\
\hline
\end{tabular}

Table 2. Influence of Epin-Extra on biometrics of potato plants in protected soil (on the average for 2008-2010)

\begin{tabular}{lccc}
\hline Variation & Plant Height, cm & Number of stems, piece./Plant & Mass of roots, g \\
\hline Cultivar Udacha & & & \\
Medium MS (control) & 42.8 & 4.2 & 27.2 \\
MS + Epin-Extra & 58.1 & 5.5 & 32.4 \\
$\mathrm{HCP}_{05}$ & 2.1 & 0.6 & 1.9 \\
Cultivar Red Scarlett & & & 26.8 \\
Medium MS (control) & 40.8 & 4.2 & 29.1 \\
$\mathrm{MS}_{\text {E Epin-Extra }}$ & 49.7 & 5.0 & 2.1 \\
$\mathrm{HCP}_{05}$ & 2.3 & 0.9 & \\
\hline
\end{tabular}

Table 3. Influence of Epin-Extra on potato productivity in protected soil (on the average for 2008-2010)

\begin{tabular}{|c|c|c|c|c|}
\hline \multirow[b]{2}{*}{ Variation } & \multicolumn{2}{|c|}{ Yield of tubers } & \multirow[b]{2}{*}{ \pm to control, $(\%)$} & \multirow[b]{2}{*}{ Number of tubers piece/plant } \\
\hline & $\mathrm{g} /$ plant & $\mathrm{t} / \mathrm{ha}$ & & \\
\hline \multicolumn{5}{|l|}{ Cultivar Udacha } \\
\hline Medium MS (control) & 366.5 & 22.2 & 100.0 & 7.1 \\
\hline MS + Epin-Extra & 464.9 & 27.9 & 125.6 & 8.9 \\
\hline $\mathrm{HCP}_{05}$ & 45.2 & & & 0.9 \\
\hline \multicolumn{5}{|l|}{ Cultivar Red Scarlett } \\
\hline Medium MS (control) & 334.7 & 20.1 & 100.0 & 7.6 \\
\hline MS + Epin-Extra & 388.3 & 23.3 & 115.9 & 9.0 \\
\hline $\mathrm{HCP}_{05}$ & 31.1 & & & 0.7 \\
\hline
\end{tabular}

Table 4. Influence of Epin-Extra onto prevalence and development of late blight on potato tops in protected soil (on the average for 2008-2010)

\begin{tabular}{|c|c|c|c|c|c|c|c|c|}
\hline \multirow[b]{2}{*}{ Variation } & \multicolumn{4}{|c|}{ Prevalence $(\%)$} & \multicolumn{4}{|c|}{ Development (\%) } \\
\hline & 2008 & 2009 & 2010 & average & 2008 & 2009 & 2010 & average \\
\hline \multicolumn{9}{|l|}{ Cultivar Udacha } \\
\hline Medium MS (control) & 8.2 & 7.9 & 5.6 & 7.2 & 7.5 & 8.0 & 5.0 & 6.8 \\
\hline MS + Epin-Extra & 2.2 & 3.1 & 1.4 & 2.2 & 3.8 & 4.2 & 2.3 & 3.4 \\
\hline $\mathrm{HCP}_{05}$ & 1.3 & 1.1 & 1.8 & & 0.9 & 1.2 & 0.5 & \\
\hline \multicolumn{9}{|l|}{ Cultivar Red Scarlett } \\
\hline Medium MS (control) & 8.9 & 8.6 & 7.8 & 8.4 & 8.0 & 8.7 & 6.9 & 7.9 \\
\hline MS + Epin-Extra & 4.7 & 5.6 & 4.0 & 4.7 & 4.5 & 4.9 & 3.7 & 4.4 \\
\hline $\mathrm{HCP}_{05}$ & 1.9 & 0.7 & 1.1 & & 1.3 & 1.6 & 1.2 & \\
\hline
\end{tabular}

\section{CONCLUSION}

The obtained data can be explained by the fact that Epin-Extra is a stress adaptogen, having a strong growthstimulating activity, which helps to increase yield and improve its quality. Growth-regulating properties of the product in addition to increasing productivity indirectly contributes to the fight against plant pathogens, increasing the immunity of plants (Kozlov, 2009; Vissey, 2003). This allows us to declare with 
certainty that this product can compete with chemical pesticides, because of its high biological activity, which ultimately leads to higher productivity of potato, using less labor cost as well as material resources and provides high quality environmentally friendly products.

As a result of the research, positive data of EpinExtra impact on plant growth and development in vitro and their subsequent productivity and resistance to late blight in protected ground were obtained. However, in the processes of these experiments we were not able to study the effect of the product on the physiological and biochemical processes (photosynthesis, the assimilation surface of the leaves, peroxidase activity, biochemical parameters) of the improved potato in a greenhouse when getting minitubers and in subsequent reproductions.

In the long term we plan to conduct physiological and biochemical studies of plants of potatoes of grades of different groups of ripeness in the conditions of the protected soil and field nurseries of reproduction. These studies are planned to be held during coming growing season.

\section{ACKNOWLEDGEMENT}

Researchers express gratitude to the director general of JSC "Elitkhoz" Anatoly Germanovich Pushkov for granting a platform (laboratory biotechnological, the hothouse complex, the revitalized plants of potatoes) for carrying out scientific researches.

\section{REFERENCES}

Anisimov, B., 2003. Phytopathogenic viruses and their control in potato seeding.

Dann, E.K. and B.J. Deuereal, 2000. Effectives of systemic resistance in bean against foliar and soilbirne pathogens as induced by biological and chemical means. Plant Pathol., 3: 324-332. DOI: 10.1046/j.1365-3059.2000.00457.x

Dospekhov, B., 1985. Methodology of experimental work. Agropromizdat.

Harmey, M.A., M.P. Growley and P.E. Clinch, 1966. The effect of growth regulators on fuberisation of cultured stem pieces of solanum tuberosum. Eur. Potato J., 9: 146-147. DOI: 10.1007/BF02364301

Hartz, T.K. and P.R. Johnstone, 2006. Relationship between soil phosphorus availability and phosphorus loss potential in runoff and drainage. Commun. Soil Sci. Plant Anal., 37: 1525-1536. DOI: 10.1080/00103620600710058
Hirsch, A.M., 1997. The role phytohormones in plantmicrobe symbiosis. Plant Soil, 194: 171-184. DOI: 10.1023/A:1004292020902

Hodyankov, A., 2008. Influence of brassinosteroids on the stability of fiber flax plants to drought. Agrochemical Vestnik.

Kagale, S., 2007. Brassinosteroid confers tolerance in Arabidopsis thaliana and Brassica narus to a range of abiotic stress. Planta, 225: 353-364. DOI: 10.1007/s00425-006-0361-6

Korp, A., 1989. Variability in potato tissue culture. Am. Potato J., 10: 669-670. DOI: 10.1007/BF02853986

Kozlov, A., 2009. Microbiological aspect in chemical soil improvement. Res. Field Agric. Sci., 2: 83-86.

Kravchenko, D., 2004. Influence of growth regulators on the development of the test-tube potato plants and their subsequent productivity in the open field. Research Institute of Agricultural Biotechnology.

Kus, J., 2000. Development and future direction of induced systemic resistance in plants. Crop Protect., 19: 859-861. DOI: 10.1016/S02612194(00)00122-8

Mohapatra, P.K., R. Patel and S.K. Sahu, 1993. Time of flowering affects grain quality and spikelet partitioning within the rice panicle. Aus. J. Plant Physiol., 20: 231-241. DOI: 10.1071/PP9930231

Persikova, T. and A. Hodyankov, 2008. Homobrassinolide natural plant hormone-an important reserve for increasing the yield and quality of flax-fiber flax. Agrochimicheskiy vestnik.

Smidt, A. and W. Negorek, 1977. Populationsdinamishce wircung von Perillus bioculatus (Tabr. Het. Pentatomidae) auf der Kartoffelkafer. Patomophaga, 12: 403-404.

Tarazanova, T. and N. Ignatiev, 2013. Biostimulator Action on yield formation and quality of potatoes. Agrochimicheskiy vesnik.

Uromova, I., 2009. Yield and quality of potato using biologics. Plodorodie.

Uromova, I., O. Shtyrlin and D. Shtyrlin, 2013. Phytoregulators as a basis for the greening of modern agricultural production. Proceedings of the International Scientific and Practical Conference: Natural and Mathematical Sciences in the Modern World, Novosibirsk: Seebak, pp: 87-88.

Vissey, J.K., 2003. Plant growth promoting rhizobacteria as biofertilizers. Plant Soil, 225: 571-586. DOI: 10.1023/A:1026037216893 